\title{
Metal-Free Fenton-like Photocatalysts Based on Covalent Organic Frameworks
}

\author{
Qiaobo Liao, ${ }^{1}$ Can Ke, ${ }^{1}$ Dongni Wang, ${ }^{1}$ Yiying Zhang, ${ }^{1}$ Qinwen Han, ${ }^{1}$ Yifan Zhang, ${ }^{1}$ and $K a i ~ X i{ }^{1,2 *}$ \\ ${ }^{1}$ School of Chemistry and Chemical Engineering, Nanjing University, 210023 Nanjing, China. \\ ${ }^{2}$ Shenzhen Research Institute of Nanjing University, Nanjing University, 581000 Shenzhen, China.
}

\begin{abstract}
The Fenton reaction is one of the most efficient and widely used advanced oxidation processes for remediating the ever-growing water pollution. Metal-free photocatalysts for Fenton-like reactions have gathered enormous scientific interest for their advantages including board $\mathrm{pH}$ operation range and high stability. Herein, we demonstrate a metal-free covalent organic framework (COF)-based standalone photocatalyst with superior reactivity and reusability for Fenton-like reactions at acid and neutral pH solutions, which can be attributed to its large porosity, high density of the photoactive triazine moiety, vertical $\pi$ arrays formed by eclipsed layer stacking and the $\beta$-ketoenamine linkage. Our experiments showed that the photocatalyst can absorb visible light effectively for activation of $\mathrm{H}_{2} \mathrm{O}_{2}$, producing abundant reactive oxygen species including superoxide radical $\left(\mathrm{O}_{2}{ }^{--}\right)$, hydroxyl radical ( $\mathrm{OH}$ ), and singlet oxygen $\left({ }^{1} \mathrm{O}_{2}\right)$ for oxidizing organic pollutants. This work not only provides an efficient metal-free photocatalyst for Fentonlike reactions, but also paves the way for COFs towards advanced oxidation processes, opening up the possibilities to their future applications in industry.
\end{abstract}

\section{INTRODUCTION}

Fenton-like reactions have been widely applied for industrial sewage treatment and pollutant control as one of the most promising advanced oxidation processes (AOPs). ${ }^{1,2}$ By activating hydrogen peroxide $\left(\mathrm{H}_{2} \mathrm{O}_{2}\right)$, peroxymonosulfate (PMS) or peroxydisulfide (PDS), Fenton-like catalysts produce highly reactive oxygen species (ROSs) including hydroxyl radical ( $\mathrm{OH})$, sulfate radical $\left(\mathrm{SO}_{4}{ }^{-}\right)$, superoxide radical $\left(\mathrm{O}_{2}{ }^{-}\right)$or singlet oxygen $\left({ }^{1} \mathrm{O}_{2}\right)$ for oxidizing organic pollutants or even mineralizing them to $\mathrm{CO}_{2}$ and $\mathrm{H}_{2} \mathrm{O}$ completely. ${ }^{3,4}$ To overcome the predicaments of the homogeneous Fenton reaction such as unrecyclability, restrictions of solution acidity, and secondary pollution, heterogeneous Fenton-like photocatalysts have gathered significant momentum over the past few years. ${ }^{5-8}$ Although significant advances have been made in the metal-containing Fenton-like photocatalysts, some problems like narrow $\mathrm{pH}$ operation range as well as oxidation and leaching of metal ions are ubiquitous in the application of these catalysts, precluding their practical applications. ${ }^{9}$ Therefore, developing metal-free Fentonlike photocatalysts is supposed to be a feasible alternative to circumvent these limitations, which is still in its infancy.

Recently, sorts of metal-free materials such as graphene $^{10}$ and g- $\mathrm{C}_{3} \mathrm{~N}_{4}{ }^{11,12}$ have been demonstrated to be able to generate strong oxidizing intermediates from oxidation agents under irradiation. These seminal works have propelled forward the development of metal-free photocatalysts for Fenton-like reactions, while it is still highly desired to enhance the reactivity. A key challenge is that most of these metal-free materials suffer from the limitations of intrinsic chemical structures which are difficult to be optimized targeting suitable band structures and desirable properties. Therefore, tedious modification processes such as chemical modifications, ${ }^{9,13}$ elemental doping, ${ }^{14}$ and formation of heterojunctions ${ }^{15,16}$ are inevitable for tailoring band structures and enhancing catalytic activities. Besides, the amorphous nature and low accessible surface areas of these materials impede the charge transfer and reduce the possibility of the contact between pollutant molecules and ROSs, which have extremely short half-life times to diffuse, impairing the performance of photocatalysts. ${ }^{4,17,18}$ To sum up, materials with regular and tailorable structures as well as large accessible surface areas are promising candidates for metal-free Fenton-like photocatalysts.

Covalent organic frameworks (COFs) have attracted great attention over the past decade. Constructed with organic building blocks linked solely by reversible covalent bonds, COFs feature low density, regular and designable structures, large porosity as well as high thermal and chemical stability, ${ }^{19-22}$ and show great potential for gas separation, ${ }^{23-25}$ pollutant adsorption, ${ }^{26,27}$ energy storage, ${ }^{28,29}$ drug delivery ${ }^{30,31}$ and photocatalysis, ${ }^{32-34}$ etc. For two-dimensional (2D) COFs, $\pi$ units are reticulated into 2D layers with predesigned topologies to form a lateral $\pi$ electronic system and stacked within atomic precision to form vertical $\pi$ columns, enabling charge transfer processes in both inter- and intra-layer directions. ${ }^{35-38}$ Taking the aforementioned criteria into account, 2D COFs are presumed 

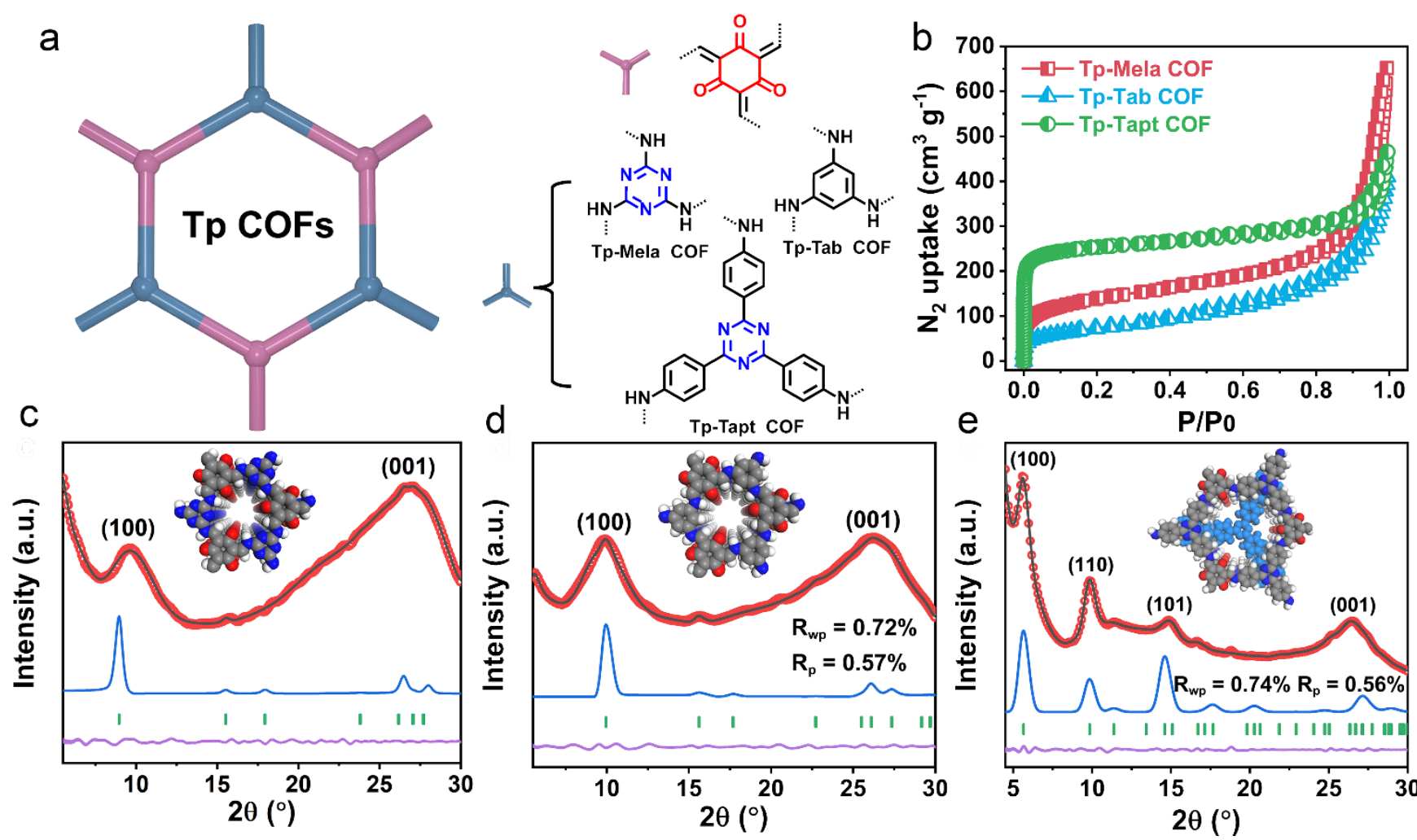

Figure 1. (a) Chemical structures of Tp-COFs reported in this work. (b) N2 sorption isotherms at $77 \mathrm{~K}$ of Tp-COFs. (c)-(e) Experimental (red), Pawley-refined (black), simulated (blue) PXRD patterns, Bragg position (green), difference (purple), and structural models (insets) of (c) Tp-Mela COF, (d) Tp-Tab COF and (e) Tp-Tapt COF.

to be suitable as an effective Fenton-like photocatalyst for their regular and designable structures, tailorable band gaps, large surface area as well as high chemical stability. Only a few COF-based catalysts for Fenton-like reactions have been reported hitherto. In these works, COFs merely served as substrates for catalysts including Fe ions, ${ }^{39}$ single-atom $\mathrm{Fe}^{40}$, or $\mathrm{g}-\mathrm{C}_{3} \mathrm{~N}_{4}{ }^{16}$, and their intrinsically catalytic performances are yet to be explored. Additionally, the COF-based photocatalysts for Fenton-like reactions have not been presented so far.

Herein, we report a metal-free photocatalyst for Fenton-like reactions based solely on COF without loading, modification, or composite forming. Considering the irreversible enol-to-keto tautomerization for chemical stable $\mathrm{COF}^{41,42}$ and the high photoactivity of triazine moiety, 43 1,3,5-triformylphloroglucinol (Tp) and melamine (Mela) were judiciously chosen to synthesize Tp-Mela COF for our study (Figure 1a), which have been reported to exhibit photoreactivity for E-Z Isomerization of Olefins and degradation of methyl orange ${ }^{44}$ and phenol ${ }^{44,45}$. For comparison, melamine was replaced with 1,3,5-triaminobenzene trihydrochloride (Tab) and 2,4,6-(4-aminophenyl)-1,3,5-triazine (Tapt), respectively, fabricating two crystalline COFs termed Tp-Tab COF and Tp-Tapt COF (Figure 1a). Among three Tp-COFs, Tp-Mela COF showed superior photocatalytic performance for Fentonlike reactions at acidic and neutral conditions, which can be attributed to its large porosity, high density of the photoactive triazine moiety, and the vertical $\pi$ arrays formed by eclipsed layer stacking. Due to the conjugated structure, the Tp-Mela COF effectively adsorbed visible light (wavelength $\lambda>420 \mathrm{~nm}$ ) to generate electrons and holes for activating $\mathrm{H}_{2} \mathrm{O}_{2}$, producing ROSs including $\mathrm{HO}_{2} / \mathrm{O}_{2}{ }^{-}, \mathrm{OH}$, and ${ }^{1} \mathrm{O}_{2}$ to oxidize organic pollutants. Thanks to the irreversible $\beta$-ketoenamine linkage, the TpMela COF exhibited superior stability and reusability. As far as we know, this is the first study to develop COFbased standalone photocatalysts for efficient Fenton-like reactions.

\section{RESULTS AND DISCUSSION}

Tp-Mela COF and Tp-Tapt COF were synthesized according to the literature methods ${ }^{43,46}$ with several revamps including the type of solvents, the concentration of the catalyst, and post-treatment methods for optimization, while the previously unreported Tp-Tab COF was prepared with similar solvothermal approaches (see Supporting Information (SI) for details). SEM images show the nanosheets of Tp-Mela COF assemble into a flower-like morphology, forming a hierarchically porous structure and providing abundantly accessible channels for organic pollutants (Figure S1a-b). Tp-Tab COF and Tp-Tapt COF were grown with sponge-like and fiber-like morphologies, 
respectively (Figure S1c-f). Two refection peaks centered at around $10^{\circ}$ and $27^{\circ}$ appeared in PXRD patterns of TpMela COF and Tp-Tab COF, which can be assigned as (100) and (001) facets, respectively, verifying their crystalline nature (Figure 1c-e). Structural simulations suggest that both COFs adopted a honeycomb (hcb) topology with an eclipsed (AA) stacking mode, possessing 1D nano-channels of $0.8 \mathrm{~nm}$ (Figure 1c-d and Figure S2-3). On the contrary, Tp-Tapt COF was proposed to stack with the staggered (AB) mode owing to the pronounced (110) and (101) peaks (Figure 1e), matching well with the simulated patterns of the AB stacking unit cell (Figure S4). Excellent agreement factors $\left(\mathrm{R}_{\mathrm{wp}}=0.33 \%\right.$ for Tp-Mela COF; $R_{\mathrm{wp}}=0.72 \%$ for Tp-Tab COF; $\mathrm{R}_{\mathrm{wp}}=0.74 \%$ for TpTapt COF, Figure 1c-e) were produced by Pawley refinement, justifying the proposed structures of Tp-COFs. Nitrogen sorption analyses at $77 \mathrm{~K}$ were carried out to determine the porosity of Tp-COFs (Figure 1b). By fitting the isotherm with Brunauer-Emmett-Teller (BET) model, specific surface areas of Tp-Mela COF, Tp-Tab COF, and Tp-Tapt COF were calculated to be $505 \mathrm{~m}^{2} \mathrm{~g}^{-1}, 253 \mathrm{~m}^{2} \mathrm{~g}$ ${ }^{1}$, and $967 \mathrm{~m}^{2} \mathrm{~g}^{-1}$, respectively (Figure S5-7). It is noteworthy that the BET surface area of Tp-Mela COF was much larger than the previously reported results with similar structures. ${ }^{43-45}$ Surprisingly, the pore volume $\left(\mathrm{P} / \mathrm{P}_{0}=\right.$ 0.99) of Tp-Mela COF $\left(0.96 \mathrm{~cm}^{3} \mathrm{~g}^{-1}\right)$ was larger than those of Tp-Tab COF $\left(0.61 \mathrm{~cm}^{3} \mathrm{~g}^{-1}\right)$ and Tp-Tapt COF $\left(0.69 \mathrm{~cm}^{3} \mathrm{~g}^{-1}\right)$, and even surpassed the theoretical value calculated by PLATON $\left(0.75 \mathrm{~cm}^{3} \mathrm{~g}^{-1}\right) .{ }^{47}$ The excess was originated from the void space in the flower-like assembly which favored mass transfer, agreeing well with the SEM result. Nonlocal density functional theory (NLDFT) revealed the pore size distributions at $0.82 \mathrm{~nm}, 0.93 \mathrm{~nm}$, and $0.87 \mathrm{~nm}$ for Tp-Mela COF, Tp-Tab COF, and Tp-Tapt COF (Figure S8), respectively, which were in line with the analyses of PXRD and structural simulations.

From the Fourier transform-infrared (FT-IR) spectra of Tp-COFs (Figure S9-11), the appearance of characteristic peaks for $\mathrm{C}=\mathrm{O}, \mathrm{C}=\mathrm{C}$, and $\mathrm{C}-\mathrm{N}$ stretching bands at 1621$1628 \mathrm{~cm}^{-1}$, 1536-1580 $\mathrm{cm}^{-1}$, and 1232-1282 $\mathrm{cm}^{-1}$ imply the transformation from enol into keto, which renders these Tp-COFs with superior structural stability. ${ }^{42}$ Solidstate ${ }^{13} \mathrm{C}$ cross-polarization magic angle spinning (CP/MAS) NMR spectra of Tp-COFs show significant signals at around $180 \mathrm{ppm}$ (183.7 ppm for Tp-Mela COF; 182.7 ppm for Tp-Tab COF; 183.6 ppm for Tp-Tapt COF, Figure S12-14), which could be assigned to carbonyl carbons in keto form, further verifying the irreversible enolto-keto tautomerization. ${ }^{42}$ Thermogravimetric analysis (TGA) curves indicate that Tp-Mela COF, Tp-Tab COF, and Tp-Tapt COF are thermally stable with decompose temperatures up to $517^{\circ} \mathrm{C}, 490^{\circ} \mathrm{C}$, and $598{ }^{\circ} \mathrm{C}$, respectively (Figure S15-17). Moreover, the Tp-Mela COF exhibited high chemical stability after treatment in $1 \mathrm{M} \mathrm{HCl}$ aqueous solutions for $24 \mathrm{~h}$ (Figure S18, red curve). Upon being submerged in $1 \mathrm{M} \mathrm{NaOH}$ for 1 day, the (001) peak decreased moderately as shown in the PXRD pattern (Figure S18, green curve), which can be explained by the partial hydrolysis of melamine moiety in $\mathrm{NaOH}$ solution. ${ }^{48}$
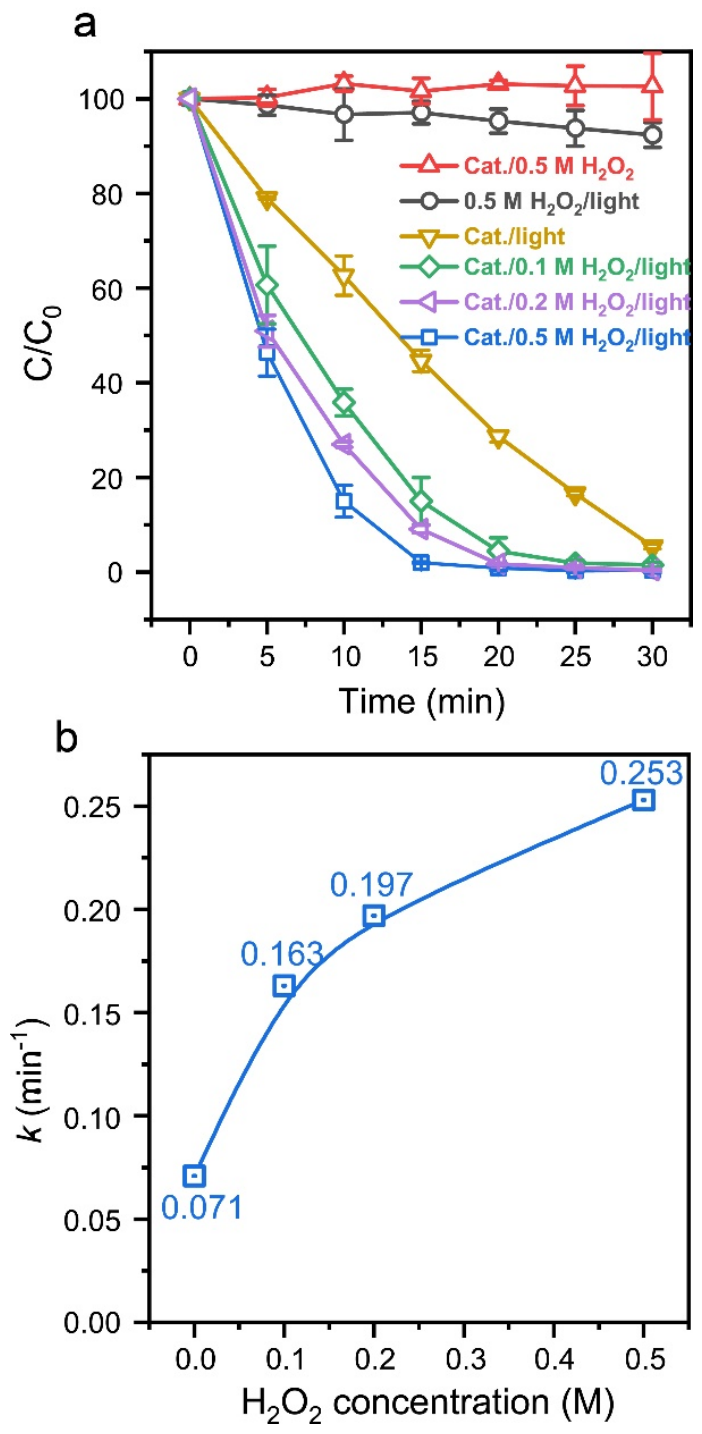

Figure 2. (a) The evolution of RhB in different reaction systems. Cat.: Tp-Mela COF; light: visible light with wavelength $\lambda>420$ $\mathrm{nm}$. (b) The apparent rate constants $(k)$ of the reactions in the presence of different $\mathrm{H}_{2} \mathrm{O}_{2}$ concentrations produced by the pseudo-firstorder model. Reaction condition: $[\mathrm{RhB}]=100 \mathrm{mg} \mathrm{L}^{-1}$, [Cat.] = $0.167 \mathrm{~g} \mathrm{~L}^{-1}, \mathrm{~T}=293 \mathrm{~K}$, initial $\mathrm{pH}=4.4$.

To evaluate the Fenton-like photocatalytic activity of Tp-COFs, rhodamine (RhB) dye was selected as the model organic pollutant. Before the photocatalytic experiments, a trial was firstly conducted to ascertain the adsorption performance of Tp-Mela COF $\left(0.167 \mathrm{~g} \mathrm{~L}^{-1}\right)$ for the aqueous $\mathrm{RhB}$ solution (100 $\mathrm{mg} \mathrm{L}^{-1}$ ), revealing that the adsorption-desorption equilibrium was achieved rapidly within 30 min with the removal efficiency of $\sim 20 \%$ and a 


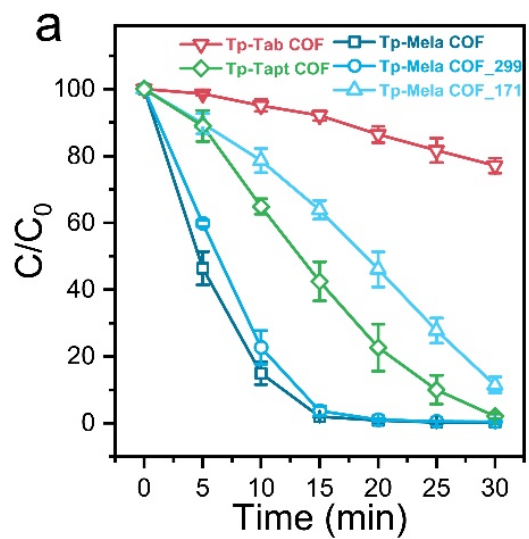

d

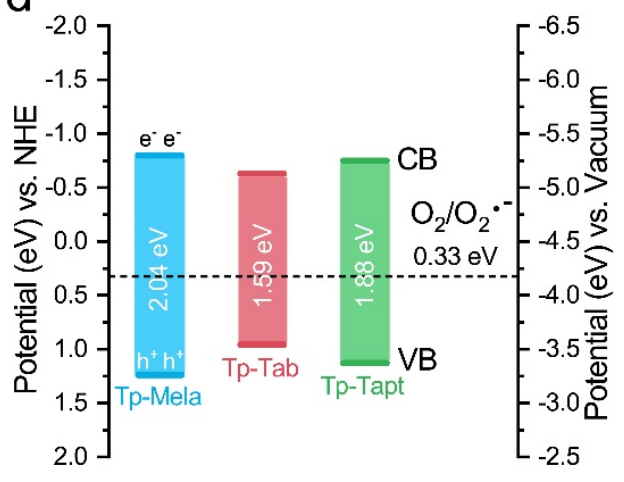

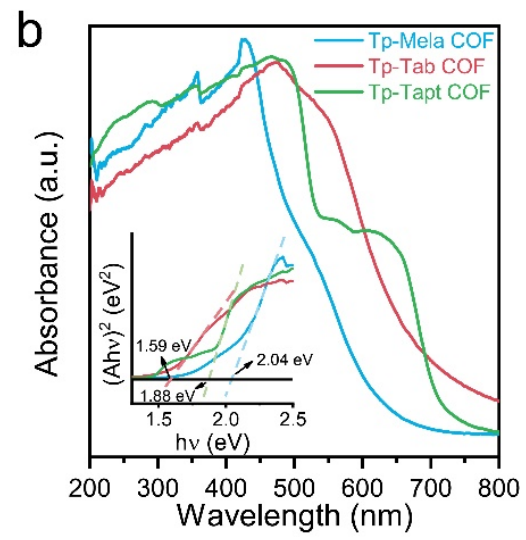

e

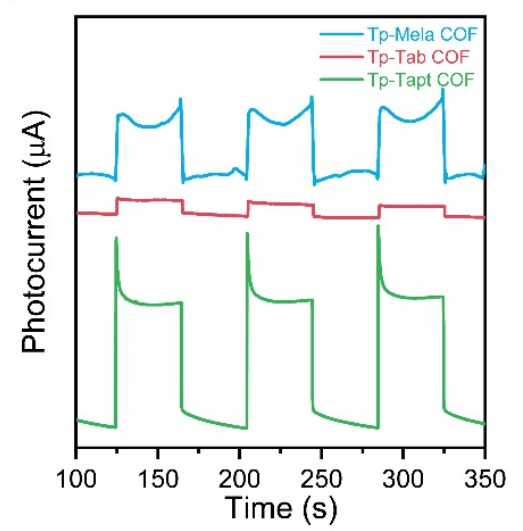

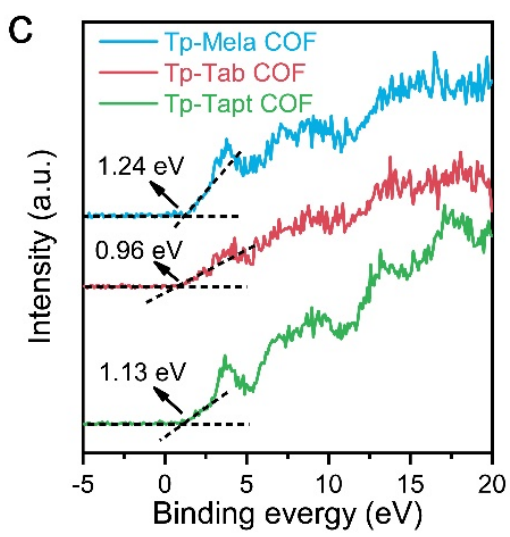

f

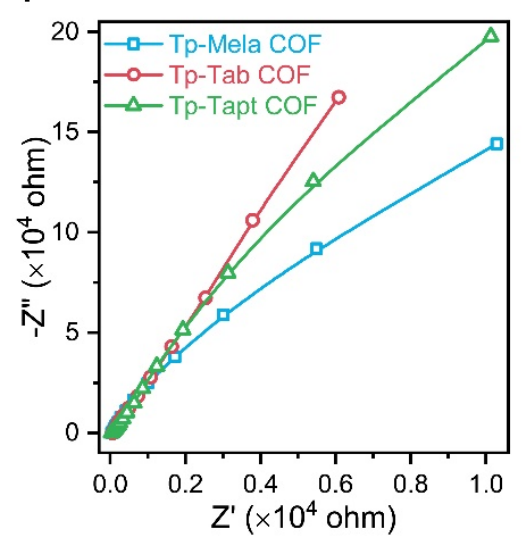

Figure 3. (a) Photocatalytic degradation of RhB over Tp-Mela COF, Tp-Mela COF_299, Tp-Mela COF_171, Tp-Tab COF and Tp-Tapt COF. Reaction condition: $[\mathrm{RhB}]=100 \mathrm{mg} \mathrm{L}^{-1}$, [Cat.] $=0.167 \mathrm{~g} \mathrm{~L}^{-1},\left[\mathrm{H}_{2} \mathrm{O}_{2}\right]=0.5 \mathrm{M}, \mathrm{T}=293 \mathrm{~K}$, initial $\mathrm{pH}=4.4$. (b) UV-vis DRS spectra and estimated band gaps (inset), (c) VBXPS spectra, (d) schematic of the band alignments, (e) transient photocurrent response and (f) EIS Nyquist plots of Tp-Mela COF, Tp-Tab COF and Tp-Tapt COF.

prominent adsorption capacity of $\sim 120 \mathrm{mg} \mathrm{g}^{-1}$ (Figure S19). The results hinted that Tp-Mela COF was highly porous to accommodate organic molecules. Based on this result, all suspensions for Fenton-like reactions were magnetically stirred in the dark for at least $1 \mathrm{~h}$ prior to the irradiation to reach the adsorption-desorption equilibrium. As shown in Figure 2a (blue curve), Tp-Mela COF exhibits high photocatalytic activity for the Fenton-like reaction. The RhB aqueous solution with a high concentration of $100 \mathrm{mg} \mathrm{L}^{-1}$ was entirely decomposed within $15 \mathrm{~min}$. In addition, the curve was fitted using the pseudo-first-order kinetic model, producing a large apparent rate constant $k$ of $0.253 \mathrm{~min}^{-1}$ (Figure S20). To shed light on the key factors for the outstanding photocatalytic activity of TpMela COF for Fenton-like reactions, several control experiments have been conducted. Figure 2a shows that the absence of Tp-Mela COF results in poor degradation performance, demonstrating that Tp-Mela COF plays an indispensable part in the catalytic system. Besides, the reaction performed in the dark was much slower than the counterpart under irradiation (Figure 2a, red curve), which confirmed the reaction was greatly driven by the visible light $(\lambda>420 \mathrm{~nm})$. It can also be observed that the addition of $\mathrm{H}_{2} \mathrm{O}_{2}$ can significantly accelerate the reaction (Figure 2a), and the $k$ value improves by $\sim 3.6$ times with the $\mathrm{H}_{2} \mathrm{O}_{2}$ concentration increasing from 0 to $0.5 \mathrm{M}$ (Figure $2 \mathrm{~b}$ and Figure S20). The result undoubtedly indicates that $\mathrm{H}_{2} \mathrm{O}_{2}$ can be activated by Tp-Mela COF with the assistance of visible light, demonstrating the reaction process was Fenton-like. Figure S21 reveals that Tp-Mela COF is highly effective over a wide $\mathrm{pH}$ range from acidic to neutral conditions ( $\mathrm{pH}=2.2$ - 7.5), providing this COFbased photocatalyst possibility for practical applications.

Considering that porosity of the catalysts plays an important role in photocatalysis, ${ }^{4,43}$ two Tp-Mela COFs with small surface areas $\left(\mathrm{S}_{\mathrm{BET}}=171 \mathrm{~m}^{2} \mathrm{~g}^{-1}\right.$ and $299 \mathrm{~m}^{2} \mathrm{~g}^{-1}$; termed Tp-Mela COF_171 and Tp-Mela COF_299, respectively) were synthesized by adjusting the concentration of acetic solutions (See SI for details). Despite their similar chemical structures, the small-surface area TpMela COFs showed lower catalytic efficiency and smaller rate constant $k$ (0.049 $\mathrm{min}^{-1}$ for Tp-Mela COF_171 and $0.229 \mathrm{~min}^{-1}$ for Tp-Mela COF_299; Figure 3a and S22). 
a

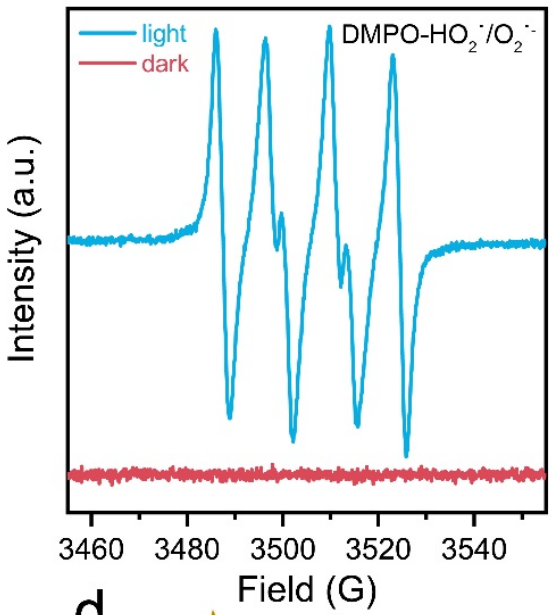

b

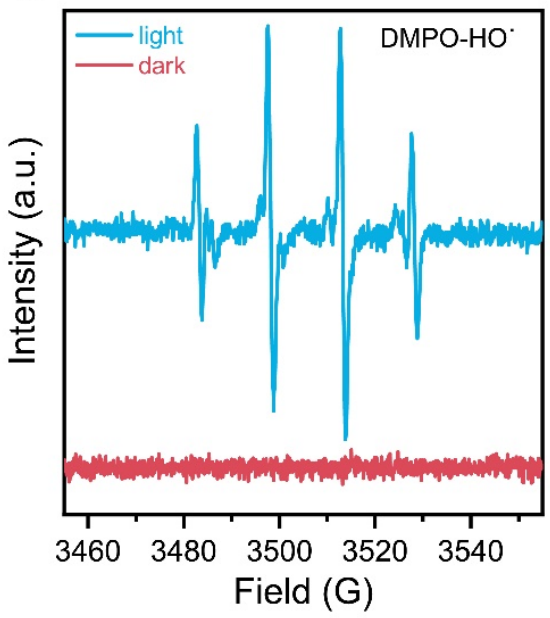

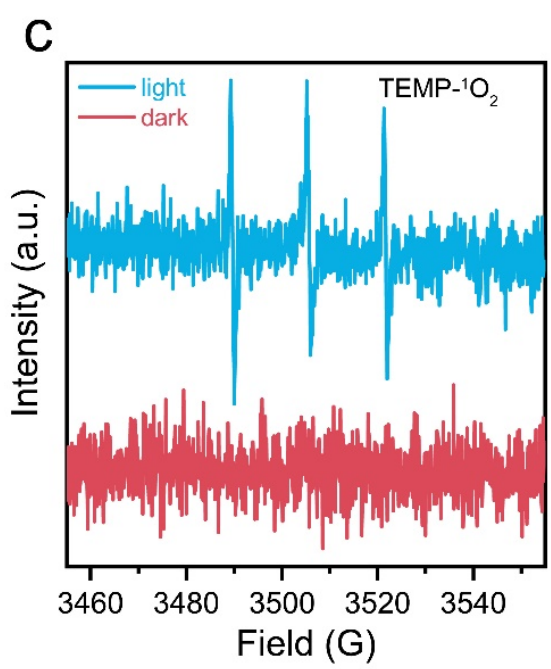
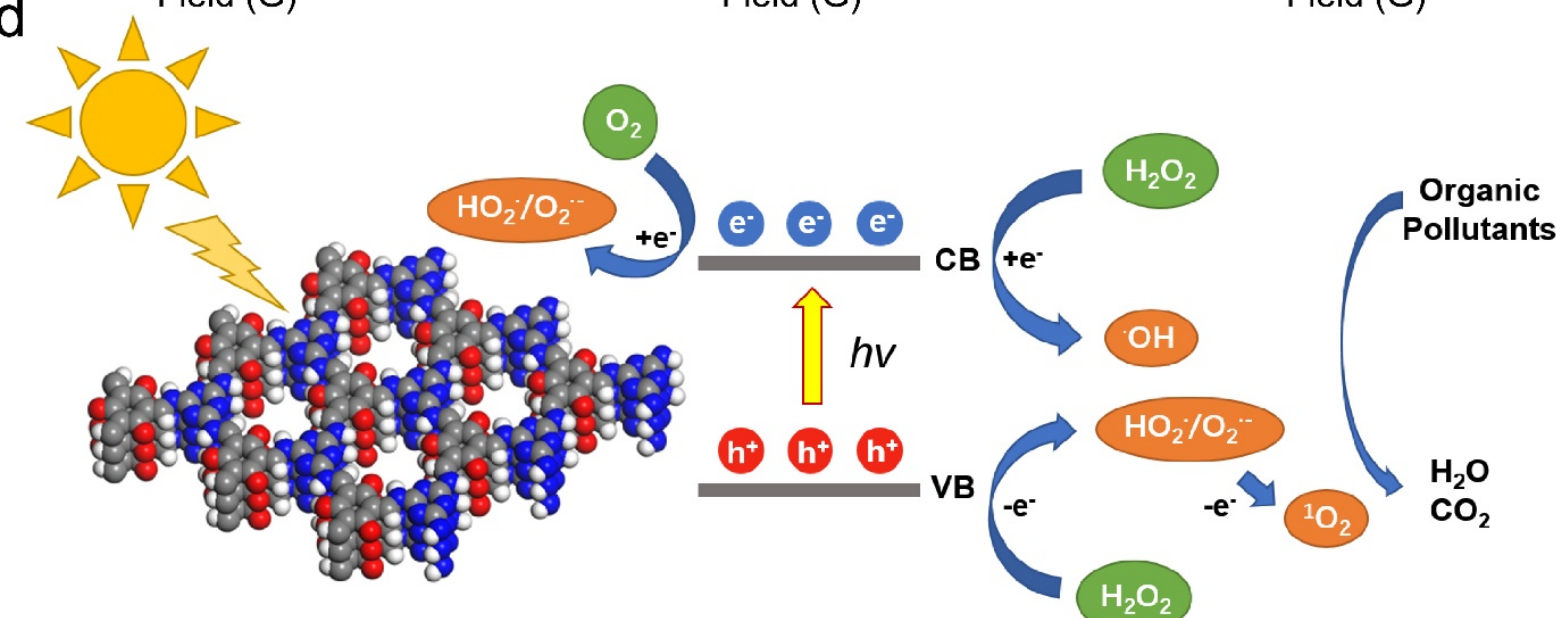

Figure 4. (a-c) EPR spectra of Tp-Mela COF/ $\mathrm{H}_{2} \mathrm{O}_{2}$ photocatalytic system in the dark and after 15 min of visible light irradiation. Conditions: (a) solvent: methanol, spin trapper: DMPO; (b) solvent: water, spin trapper: DMPO; (c) solvent: water, spin trapper: TEMP. (d) Proposed mechanism of Fenton-like reaction with Tp-Mela COF/ $\mathrm{H}_{2} \mathrm{O}_{2}$ photocatalytic system.

It can be explained that the larger porosity of Tp-Mela COF enabled $\mathrm{H}_{2} \mathrm{O}_{2}$ and organic molecules accessible to interior active sites, by providing much more channels. Besides Tp-Mela COF, the photocatalytic activities of TpTab COF and Tp-Tapt COF were also measured as shown in Figure 3a and Figure S22. Obviously, Tp-Mela COF far outperformed Tp-Tab COF, with a $k$ value 31.6 times larger than that of the latter $\left(0.253 \mathrm{~min}^{-1}\right.$ vs. $\left.0.008 \mathrm{~min}^{-1}\right)$, indicative of the vital role of photoactive triazine cores stitched into the framework. On the other hand, despite its larger surface area, Tp-Tapt COF also gave a smaller $k$ value compared to that of Tp-Mela COF (0.092 min $^{-1}$ vs. $0.253 \mathrm{~min}^{-1}$ ), which might be attributed to structural factors including the higher triazine density of Tp-Mela COF and their different stacking modes.

Optic and electronic properties of Tp-COFs were then investigated to provide deep insight into the mechanism of the photocatalytic activity. Due to the conjugated structures, Tp-COFs exhibited wide visible light absorption ranges suggested by UV-vis diffuse reflection spectroscopy (DRS), corresponding to narrow bandgaps of 2.04 $\mathrm{eV}, 1.59 \mathrm{eV}$, and $1.88 \mathrm{eV}$, respectively (Figure 3b, inset). The electronic positions of valence bands (VB) determined by valence band $\mathrm{X}$-ray photoelectron spectroscopy (VBXPS) were $1.24 \mathrm{eV}, 0.96 \mathrm{eV}$, and $1.13 \mathrm{eV}$ for Tp-Mela COF, Tp-Tab COF, and Tp-Tapt COF, respectively (Figure $3 c$ ), and their conduction bands (CB) were calculated to be $-0.80 \mathrm{eV},-0.63 \mathrm{eV}$ and $-0.75 \mathrm{eV}$ (Figure $3 \mathrm{~d}$ ). Among three Tp-COFs, Tp-Mela COF possessed the most positive $\mathrm{VB}$ and the most negative $\mathrm{CB}$, which endowed it with stronger oxidation and reduction capabilities. ${ }^{44}$ The transient photocurrent intensities in several on-off cycles under intermittent visible-light irradiation of Tp-Mela COF and Tp-Tapt COF were much higher than that of Tp-Tab $\mathrm{COF}$, indicating a more efficient charge separation in 
these two COFs with inlaid triazine cores. ${ }^{49-51}$ It is noteworthy that the photocurrent of Tp-Tapt COF was even larger than that of Tp-Mela COF, which was not in accordance with the photocatalytic activities. The phenomenon can be attributed to the abundant negatively charged $\mathrm{O}_{2}{ }^{-}$radical anions generated on the grain boundary, creating a high potential barrier that reduced the photocurrent. ${ }^{52}$ Furthermore, the electronic impedance spectroscopy (EIS) analyses were conducted on the Tp-COFs. As shown in Figure 3f, the diameter of the Nyquist plot of Tp-Mela COF is smaller relative to those of Tp-Tab COF and Tp-Tapt COF, reflecting that the charge transfer resistance at the interface of Tp-Mela COF is lower, which favors the transportation of photogenerated charge carriers. ${ }^{53,54}$ Despite the inlaid triazine cores, high crystallinity, and large porosity of Tp-Tapt COF, the high charge transfer resistance deteriorated its photocatalytic activity, which could be contributed to the AB stacking mode with discontinuous vertical $\pi$ columns which blocks channels for transferring charge. ${ }^{55}$

To ascertain the mechanism of the photocatalytic system for Fenton-like reaction, the electron paramagnetic resonance (EPR) spectroscopic analyses were conducted to distinguish ROSs involved in the reaction, using 5, 5dimethylpyrroline-1-oxide (DMPO) and 2, 2, 6, 6-tetramethylpiperiding (TEMP) as spin trappers. Under the dark environment, no obvious signal appeared in all EPR spectra of the Tp-Mela $\mathrm{COF} / \mathrm{H}_{2} \mathrm{O}_{2}$ system (Figure 4a-c), verifying the visible light was a prerequisite to produce ROSs. In contrast, the EPR spectrum of the Tp-Mela $\mathrm{COF} / \mathrm{H}_{2} \mathrm{O}_{2} /$ light system conducted in methanol shows strong signals of DMPO- $\mathrm{HO}_{2}{ }^{\circ} / \mathrm{O}_{2}{ }^{-}$adducts (Figure $4 \mathrm{a}$ ). Besides, moderate peaks of DMPO- $\mathrm{OH}$ adducts with 1:2:2:1 quartet characteristic and TEMP- ${ }^{1} \mathrm{O}_{2}$ adducts with 1:1:1 triplet characteristic emerged after 15 min of irradiation (Figure 4b-c). The results provide direct evidence that ROSs including $\mathrm{HO}_{2} / \mathrm{O}_{2}{ }^{--},{ }^{\circ} \mathrm{OH}$ and ${ }^{1} \mathrm{O}_{2}$ could be generated in this system under irradiation while the $\mathrm{HO}_{2} / \mathrm{O}_{2}{ }^{-}$ played the dominant role. According to the above analyses, the mechanism for the photocatalytic Fenton-like reaction based on the Tp-Mela $\mathrm{COF} / \mathrm{H}_{2} \mathrm{O}_{2}$ system is proposed in Figure 4d. First, the photons with energy higher than the bandgap excited electrons which then migrated from the VB to the CB. Second, $\mathrm{H}_{2} \mathrm{O}_{2}$ molecules were reduced and oxidized by photo-excited electrons and holes respectively, producing the aggressive species ${ }^{\circ} \mathrm{OH}$ and the moderate species $\mathrm{HO}_{2} / \mathrm{O}_{2} \cdot$, which can be further transformed into ${ }^{1} \mathrm{O}_{2}{ }^{9,56}$ Meanwhile, partial $\mathrm{HO}_{2}{ }^{\circ} / \mathrm{O}_{2}{ }^{\cdot}$ was generated from the reduction of dissolved oxygen as reported previously. ${ }^{44,45}$ Finally, the absorbed pollutant molecules were efficiently consumed and mineralized by ROSs.
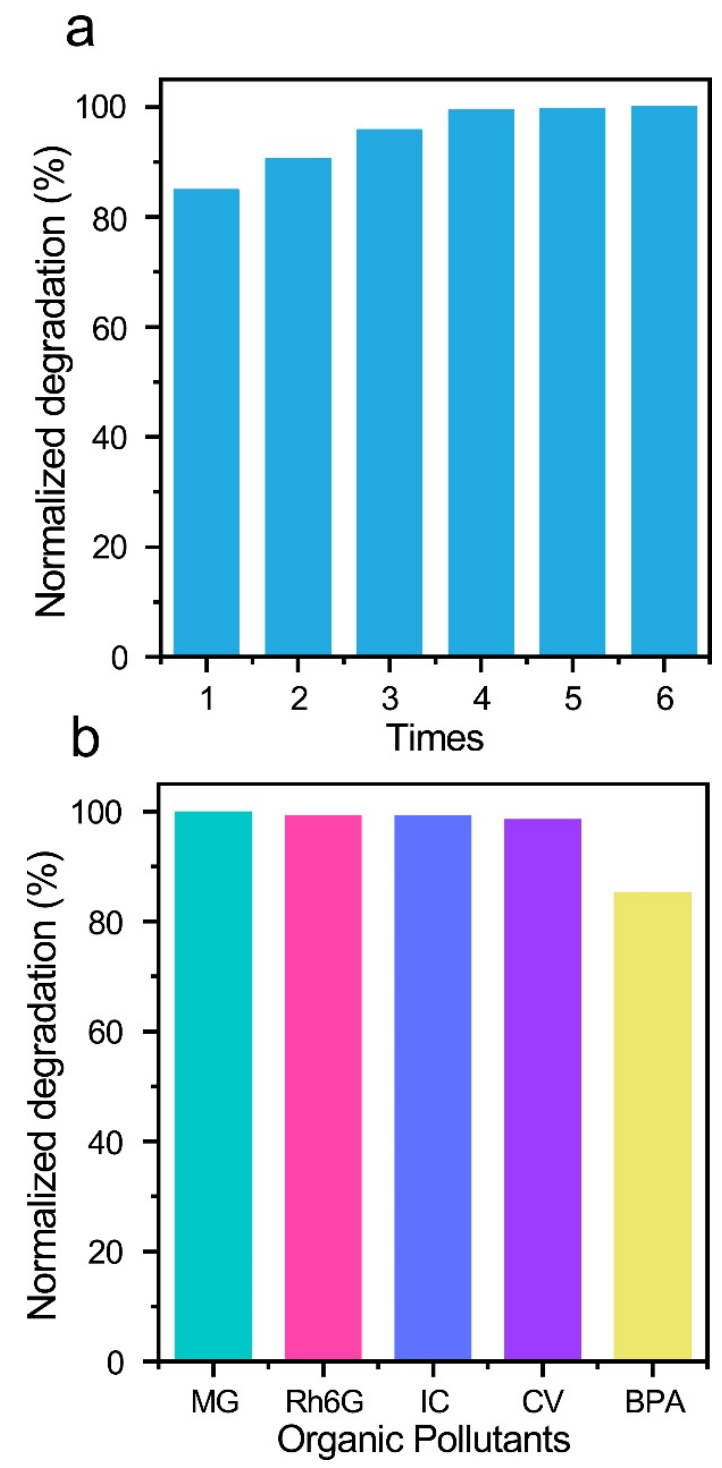

Figure 5. (a) Recycling degradation efficiency of RhB over TpMela $\mathrm{COF} / \mathrm{H}_{2} \mathrm{O}_{2}$ photocatalytic Fenton-like system. Reaction condition: $[\mathrm{RhB}]=100 \mathrm{mg} \mathrm{L}^{-1}$, [Cat.] (1st run) $=1.0 \mathrm{~g} \mathrm{~L}^{-1},\left[\mathrm{H}_{2} \mathrm{O}_{2}\right]=$ $0.5 \mathrm{M}, \mathrm{T}=293 \mathrm{~K}$, irradiation time: $30 \mathrm{~min}$, initial $\mathrm{pH}=4.4$. (b) Degradation efficiencies of various organic pollutants over TpMela $\mathrm{COF} / \mathrm{H}_{2} \mathrm{O}_{2}$ photocatalytic Fenton-like system. Reaction condition: $[\mathrm{MG}]=150 \mathrm{mg} \mathrm{L}^{-1}$, [Rh6G] $=50 \mathrm{mg} \mathrm{L}^{-1}$, [IC] $=250 \mathrm{mg} \mathrm{L}$ ${ }^{1},[\mathrm{CV}]=50 \mathrm{mg} \mathrm{L}^{-1}$, [BPA] $=50 \mathrm{mg} \mathrm{L}^{-1}$, [Cat.] $=0.167 \mathrm{~g} \mathrm{~L}^{-1},\left[\mathrm{H}_{2} \mathrm{O}_{2}\right]$ $=0.5 \mathrm{M}, \mathrm{T}=293 \mathrm{~K}$, irradiation time: $30 \mathrm{~min}$.

To explore the recyclability of Tp-Mela COF, the catalyst was recollected, filtrated, rinsed, dried, and reused in sequence runs for 5 times. Much to our delight, the degradation efficiency retained as high as $100 \%$ even in the sixth run, demonstrating the excellent reusability of TpMela COF (Figure 5a). It should be noted that a high concentration $\left(1.0 \mathrm{~g} \mathrm{~L}^{-1}\right)$ of Tp-Mela COF was applied initially to ensure that enough samples can be recycled in the last run. The decreased degradation efficiency in the first few runs could be caused by an excess dosage of Tp-Mela COF due to light scattering and light blocking effects. ${ }^{12}$ PXRD pattern shows that the crystallinity of the COF is 
preserved after the sixth run, further verifying its structural stability which can be ascribed to the $\beta$-ketoenamine linkage (Figure S23). Aside from RhB, several common organic pollutants including malachite green (MG), rhodamine 6G (Rh6G), indigo carmine (IC), crystal violet (CV), and bisphenol A (BPA) were tested in the photocatalytic system to examine its generality. As displayed in Figure 5b, nearly $100 \%$ of MG, Rh6G, IC, and CV were degraded within a short reaction time of $30 \mathrm{~min}$. For BPA, a typical endocrine disruptive compound (EDC), a high degradation efficiency of $85 \%$ was achieved after the 30 min irradiation with an apparent rate constant $k$ of 0.064 $\min ^{-1}$ (Figure S24). The results reveal that Tp-Mela $\mathrm{COF} / \mathrm{H}_{2} \mathrm{O}_{2}$ is a broad-spectrum photocatalytic system for degrading pollutants over a wide range.

\section{CONCLUSION}

To summarize, we have developed a metal-free photocatalytic system based on Tp-Mela COF/ $\mathrm{H}_{2} \mathrm{O}_{2}$ for Fenton-like reactions. Benefiting from its large porosity, high density of the photoactive triazine moiety, the vertical $\pi$ arrays formed by eclipsed layer stacking, and the strong $\beta$-ketoenamine linkage, the Tp-Mela COF-based standalone photocatalyst exhibited excellent activity for degradation of organic pollutants at acidic and neutral conditions, by activating the green oxidant $\mathrm{H}_{2} \mathrm{O}_{2}$. The mechanism study showed that ROSs including $\mathrm{HO}_{2}{ }^{\circ} / \mathrm{O}_{2}{ }^{-}, \mathrm{OH}$, and ${ }^{1} \mathrm{O}_{2}$ were produced by the photocatalytic system, which was responsible for the high efficiency of the Fenton-like reaction. Moreover, Tp-Mela $\mathrm{COF} / \mathrm{H}_{2} \mathrm{O}_{2}$ photocatalytic system showed superior reusability and was found to be a broad-spectrum system for photocatalytic degradation of versatile organic pollutants. This work not only provides a high effective metal-free photocatalyst for Fenton-like reactions but also paves an avenue for COF materials towards advanced oxidation processes for practical sewage treatment and environmental remediation.

\section{ASSOCIATED CONTENT}

Supporting Information. This material is available free of charge via the Internet at http://pubs.acs.org.

Materials and instruments, synthesis and characterization of TpCOFs, structural simulation for Tp-COFs, and experimental details of Fenton-like reactions (PDF)

Crystal structure of Pawley-refined Tp-Mela COF with AA stacking mode (CIF)

Crystal structure of Pawley-refined Tp-Tab COF with AA stacking mode (CIF)

Crystal structure of Pawley-refined Tp-Tapt COF with AB stacking mode (CIF)

\section{AUTHOR INFORMATION}

\section{Corresponding Author}

*xikai@nju.edu.cn

\section{Notes}

Any additional relevant notes should be placed here.

\section{ACKNOWLEDGMENT}

This work was supported by the Ministry of Science and Technology of China (2017YFA0700500), Shenzhen Science and Technology Innovation Committee (No. JCYJ20180307151441165), and the Fundamental Research Funds for the Central Universities (No. 020514380221).

\section{REFERENCES}

(1) Shannon, M. A.; Bohn, P. W.; Elimelech, M.; Georgiadis, J. G.; Mariñas, B. J.; Mayes, A. M. Nature 2008, 452, 301-310.

(2) Gupta, S. S.; Stadler, M.; Noser, C. A.; Ghosh, A.; Steinhoff, B.; Lenoir, D.; Horwitz, C. P.; Schramm, K. W.; Collins, T. J. Science 2002, 296, $326-328$

(3) Wei, Z.; Liang, F.; Liu, Y.; Luo, W.; Wang, J.; Yao, W.; Zhu, Y. Appl. Catal. B-Environ. 2017, 201, 600-606.

(4) Li, X.; Huang, X.; Xi, S.; Miao, S.; Ding, J.; Cai, W.; Liu, S.; Yang, X.; Yang, H.; Gao, J.; Wang, J.; Huang, Y.; Zhang, T.; Liu, B. J. Am. Chem. Soc. 2018, 140, 12469-12475.

(5) Wang, N.; Zhu, L.; Lei, M.; She, Y.; Cao, M.; Tang, H. ACS Catal. 2011, 1, 1193-1202.

(6) Deng, Y.; Xing, M.; Zhang, J. Appl. Catal. B-Environ. 2017, 211, 157-166.

(7) Hu, J.; Zhang, P.; An, W.; Liu, L.; Liang, Y.; Cui, W. Appl. Catal. B-Environ. 2019, 245, 130-142.

(8) Zhu, Y.; Zhu, R.; Xi, Y.; Zhu, J.; Zhu, G.; He, H. Appl. Catal. BEnviron. 2019, 255, 117739.

(9) Lyu, L.; Yu, G.; Zhang, L.; Hu, C.; Sun, Y. Environ. Sci. Technol. 2018, 52, 747-756.

(10) Espinosa, J. C.; Navalón, S.; Álvaro, M.; García, H. ChemCatChem 2016, 8, 2642-2648.

(11) Cui, Y.; Ding, Z.; Liu, P.; Antonietti, M.; Fu, X.; Wang, X. Phys. Chem. Chem. Phys. 2012, 14, 1455-1462.

(12) Yue, D.; Qian, X.; Kan, M.; Fang, M.; Jia, J.; Yang, X.; Zhao, Y. Appl. Catal. B-Environ. 2018, 229, 211-217.

(13) Wu, F.; Huang, H.; Xu, T.; Lu, W.; Li, N.; Chen, W. Appl. Catal. B-Environ. 2017, 218, 230-239.

(14) Lin, K. Y. A.; Zhang, Z. Y. Chem. Eng. J. 2017, 313, 1320-1327.

(15) Wei, M.; Gao, L.; Li, J.; Fang, J.; Cai, W.; Li, X.; Xu, A. J. Hazard. Mater. 2016, 316, 60-68.

(16) Yao, Y.; Hu, Y.; Hu, H.; Chen, L.; Yu, M.; Gao, M.; Wang, S. J. Colloid. Interf. Sci. 2019, 554, 376-387.

(17) Olmez-Hanci, T.; Arslan-Alaton, I. Chem. Eng. J. 2013, 224, 10 16.

(18) Dharmaraja, A. T.; Chakrapani, H. Org. Lett. 2014, 16, 398-401.

(19) Côté, A. P.; Benin, A. I.; Ockwig, N. W.; O’Keeffe, M.; Matzger, A. J.; Yaghi, O. M. Science 2005, 310, 1166 - 1170.

(20) Lyle, S. J.; Waller, P. J.; Yaghi, O. M. Trends Chem. 2019, 1, 172184.

(21) Rodríguez-San-Miguel, D.; Zamora, F. Chem. Soc. Rev. 2019, 48, 4375-4386.

(22) Wang, J.; Zhuang, S. Coordin. Chem. Rev. 2019, 400, 213046.

(23) Huang, N.; Chen, X.; Krishna, R.; Jiang, D. Angew. Chem. Int. Ed. 2015, 54, 2986-2990.

(24) Tuci, G.; Pilaski, M.; Ba, H.; Rossin, A.; Luconi, L.; Caporali, S.; Pham-Huu, C.; Palkovits, R.; Giambastiani, G. Adv. Funct. Mater. 2017, 27, 1605672. 
(25) Wang, G.; Leus, K.; Jena, H. S.; Krishnaraj, C.; Zhao, S.; Depauw, H.; Tahir, N.; Liu, Y.-Y.; Van Der Voort, P. J. Mater. Chem. A 2018 6, 6370-6375.

(26) Sun, Q.; Aguila, B.; Perman, J. A.; Butts, T.; Xiao, F.-S.; Ma, S. Chem 2018, 4, 1726-1739.

(27) Liao, Q.; Ke, C.; Huang, X.; Zhang, G.; Zhang, Q.; Zhang, Z.; Zhang, Y.; Liu, Y.; Ning, F.; Xi, K. J. Mater. Chem. A 2019, 7, 1895918970.

(28) Lei, Z.; Yang, Q.; Xu, Y.; Guo, S.; Sun, W.; Liu, H.; Lv, L. P.; Zhang, Y.; Wang, Y. Nat. Commun. 2018, 9, 1-13.

(29) Xu, F.; Yang, S.; Chen, X.; Liu, Q.; Li, H.; Wang, H.; Wei, B.; Jiang, D. Chem. Sci. 2019, 10, 6001-6006.

(30) Zhang, Y.; Zhang, L.; Wang, Z.; Wang, F.; Kang, L.; Cao, F.; Dong, K.; Ren, J.; Qu, X. Biomaterials 2019, 223, 119462.

(31) Zhang, G.; Li, X.; Liao, Q.; Liu, Y.; Xi, K.; Huang, W.; Jia, X. Nat. Commun. 2018, 9, 2785.

(32) Wang, X.; Chen, L.; Chong, S. Y.; Little, M. A.; Wu, Y.; Zhu, W. H.; Clowes, R.; Yan, Y.; Zwijnenburg, M. A.; Sprick, R. S.; et al. Nat. Chem. 2018, 10, 1180-1189.

(33) Wei, P.-F.; Qi, M.-Z.; Wang, Z.-P.; Ding, S.-Y.; Yu, W.; Liu, Q.; Wang, L.-K.; Wang, H.-Z.; An, W.-K.; Wang, W. J. Am. Chem. Soc. 2018, 140, 4623-4631.

(34) Liao, Q.; Xu, W.; Huang, X.; Ke, C.; Zhang, Q.; Xi, K.; Xie, J. Sci. China Chem. 2020, 63, 707-714.

(35) Ding, X.; Chen, L.; Honsho, Y.; Feng, X.; Saengsawang, O.; Guo, J.; Saeki, A.; Seki, S.; Irle, S.; Nagase, S.; et al. J. Am. Chem. Soc. 2011, 133, 14510-14513.

(36) Feng, X.; Chen, L.; Honsho, Y.; Saengsawang, O.; Liu, L.; Wang, L.; Saeki, A.; Irle, S.; Seki, S.; Dong, Y.; et al. Adv. Mater. 2012, 24, 3026-3031.

(37) Sun, B.; Zhu, C.-H.; Liu, Y.; Wang, C.; Wan, L.-J.; Wang, D. Chem. Mater. 2017, 29, 4367-4374.

(38) Meng, Z.; Stolz, R. M.; Mirica, K. A. J. Am. Chem. Soc. 2019, 141, 11929-11937.

(39) Liu, Y.; Wang, Y.; Li, H.; Guan, X.; Zhu, L.; Xue, M.; Yan, Y.; Valtchev, V.; Qiu, S.; Fang, Q. Chem. Sci. 2019, 10, 10815-10820.
(40) Yao, Y.; Yin, H.; Gao, M.; Hu, Y.; Hu, H.; Yu, M.; Wang, S. Chem. Eng. Sci. 2019, 209, 115211.

(41) Zhao, Y.-P.; Yang, L.-Y.; Liu, R. S. H. Green Chem. 2009, 11, 837-842.

(42) Kandambeth, S.; Mallick, A.; Lukose, B.; Mane, M. V; Heine, T.; Banerjee, R. J. Am. Chem. Soc. 2012, 134, 19524-19527.

(43) Bhadra, M.; Kandambeth, S.; Sahoo, M. K.; Addicoat, M.; Balaraman, E.; Banerjee, R. J. Am. Chem. Soc. 2019, 141, 6152-6156.

(44) He, S.; Rong, Q.; Niu, H.; Cai, Y. Chem. Commun. 2017, 53, 9636-9639.

(45) Lv, H.; Zhao, X.; Niu, H.; He, S.; Tang, Z.; Wu, F.; Giesy, J. P. J. Hazard. Mater. 2019, 369, 494-502.

(46) Wang, R.; Kong, W.; Zhou, T.; Wang, C.; Guo, J. Chem. Commun. 2021, 57, 331-334.

(47) Spek, A. L. J. Appl. Cryst. 2003, 36, 7-13.

(48) Gong, H.; Tang, S.; Zhang, T. React. Kinet. Mech. Cat. 2016, 118, 377-391.

(49) Li, Z.; Zhi, Y.; Shao, P.; Xia, H.; Li, G.; Feng, X.; Chen, X.; Shi, Z.; Liu, X. Appl. Catal. B-Environ. 2019, 245, 334-342.

(50) Huang, X.; Wu, Z.; Zheng, H.; Dong, W.; Wang, G. Green Chem. 2018, 20, 664-670.

(51) Zhang, J.; Zhang, M.; Lin, S.; Fu, X.; Wang, X. J. Catal. 2014, 310, 24-30.

(52) Liu, Y.; Xie, C.; Li, J.; Zou, T.; Zeng, D. Appl. Catal. A-Gen. 2012, 433-434, 81-87.

(53) Zhang, J.; Chen, X.; Takanabe, K.; Maeda, K.; Domen, K.; Epping, J. D.; Fu, X.; Antonietti, M.; Wang, X. Angew. Chem. Int. Ed. 2010, 49, 441-444.

(54) Deng, Y.; Zhang, Z.; Du, P.; Ning, X.; Wang, Y.; Zhang, D.; Liu, J.; Zhang, S.; Lu, X. Angew. Chem. Int. Ed. 2020, 59, 6082-6089.

(55) Xiong, Y.; Liao, Q.; Huang, Z.; Huang, X.; Ke, C.; Zhu, H.; Dong, C.; Wang, H.; Xi, K.; Zhan, P.; et al. Adv. Mater. 2020, 32, 1907242.

(56) Espinosa, J. C.; Navalón, S.; Primo, A.; Moral, M.; Sanz, J. F.; Álvaro, M.; García, H. Chem. Eur. J. 2015, 21, 11966-11971. 
Table of Contents (TOC)

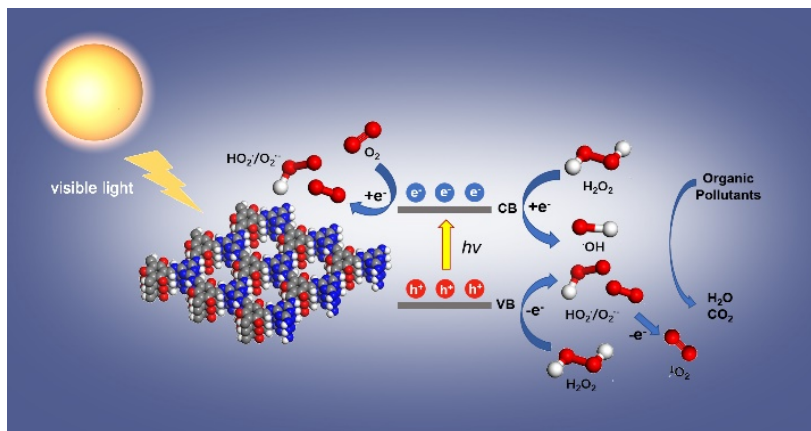

